\title{
Effect of aromatase inhibitor, letrozole on semen parameters in eugonadotropic hypoandrogenic men with oligozoospermia
}

\author{
Jahan I.*, Ishrat S., Banu J., Fatima P., Ansary S. A., Afrin S., Nasreen K.
}

Department of Reproductive Endocrinology and Infertility BSMMU, Dhaka, Bangladesh

Received: 10 January 2021

Accepted: 10 February 2021

\section{*Correspondence:}

Dr. Jahan I.,

E-mail: dr.ijahan.k52@gmail.com

Copyright: $(\subset)$ the author(s), publisher and licensee Medip Academy. This is an open-access article distributed under the terms of the Creative Commons Attribution Non-Commercial License, which permits unrestricted non-commercial use, distribution, and reproduction in any medium, provided the original work is properly cited.

\begin{abstract}
Background: Some men with severely defective sperm production commonly have excess aromatase activity, reflected by low serum testosterone and relatively elevated estradiol levels. Elevated levels of estrogen lead to feedback inhibition of the hypothalamic -pituitary-gonadal axis, and the end result is a decrease in LH necessary for the production of testosterone, and FSH to optimize sperm production. The aim of this study was to evaluate the effect of aromatase inhibitor, letrozole on the semen parameters of infertile male having oligozoospermia, low serum testosterone level and testosterone to estradiol ratio $<10$.

Methods: This Prospective study was conducted in the Department of Reproductive Endocrinology and Infertility at Bangabandhu Sheikh Mujib Medical University, Dhaka, Bangladesh during the period from May 2019 to April 2020. The sample size was 30 subfertile men with oligozoospermia $(\leq 10 \mathrm{million} / \mathrm{ml})$, low serum testosterone level $(<300$ $\mathrm{ng} / \mathrm{dl})$ and low testosterone to estradiol ratio $(<10)$. All patients were treated with letrozole $2.5 \mathrm{mg}$ daily for 4 months. At the end of the 4 months the semen analysis was performed. Statistical analysis was carried out by using IBM Statistical Package for Social Sciences version 25 for windows (SPSS version 25.0).

Results: The sperm concentration, sperm motility and total motile sperm count significantly increased after letrozole treatment. The side effects were mild and well tolerated.

Conclusions: This study suggests that some men with oligozoospermia, low serum testosterone levels and normal gonadotropin concentration may have a treatable endocrinopathy. Letrozole may be used to improve sperm parameters in infertile men with low serum testosterone to estradiol ratio.
\end{abstract}

Keywords: Aromatase inhibitor, Estradiol, Letrozole, Male infertility, Oligozoospermia, Testosterone

\section{INTRODUCTION}

Infertility affects as an estimated $15 \%$ couples globally, amounting to 48.5 million couples and approximately $50 \%$ of this is because of male factors. ${ }^{1}$ Approximately $8 \%$ of men on reproductive age seek medical attention for infertility problems. Up to $10 \%$ of these men present with a reversible cause affecting their fertility potential. ${ }^{2}$ Testicular function involves both the production of testosterone and spermatogenesis, and this function is highly regulated by hypothalamic-pituitary-gonadal axis. Spermatogenesis is dependent on maintenance of high levels of intra-testicular testosterone and follicle stimulating hormone stimulation of the sertoli cells. ${ }^{3}$ Despite the requirement of testosterone for spermatogenesis, the administration of testosterone and other androgens have contraceptive properties; they exhibit a negative feedback on hypothalamic pituitary gonadal axis and thus inhibit luteinizing hormone stimulation of intra-testicular testosterone production, as well as FSH stimulation of sertoli cells, and should be avoided. The majority of male infertility is idiopathic. However, there are multiple known causes of male infertility and several conditions have a pharmacologic option as the first line of treatment. For most known causes of male infertility, the therapeutic goal is the 
maintenance of the reproductive axis to increase testicular testosterone. For men with idiopathic infertility, as there are no reliable treatments to enhance fertility the medical management tends to be empirical and is directed for the purposes of optimization. However, increased sperm production or motility has been associated with empiric medical therapy using estrogen receptor modulators such as clomiphene citrate or tamoxifen citrate. Unfortunately, use of estrogen receptor modulators results in increased estrogen levels as well increased testosterone production. ${ }^{4}$ Recent studies have identified a potential specific endocrine defect in men with severe male factor infertility. 5 Some men with severely impaired sperm production have a relative excess of estrogen to testosterone, quantitatively measured as an increased testosterone/estradiol (T/E2) ratio. Estrogen may also have direct adverse effects on the germinal epithelium. Pavlovich et al characterized men with severe male factor infertility as having a testosterone to estradiol ratio of 6.9; whereas men with normal spermatogenesis had a mean testosterone to estradiol ratio of 14.5. Based on these observations, they proposed a cut- point of 10 as the lower limit of normal testosterone to estradiol ratios of men (calculated using testosterone in $\mathrm{ng} / \mathrm{dl}$ and estrogen as $\mathrm{pg} / \mathrm{ml}) .{ }^{5}$ High estrogen levels in combination with low testosterone levels have been shown to impair proper spermatogenesis. ${ }^{4}$ More importantly, elevated levels of estrogen will lead to feedback inhibition of the hypothalamo-gonadal-pituitary axis and the end result is a decrease in the LH necessary for the production of testosterone and FSH to optimize sperm production. ${ }^{6}$ Aromatase is a cytochrome p-450 enzyme that converts testosterone to estradiol and androstenedione to estrone. Aromatase can be found in female reproductive tract, testis, liver, and brain. In the testis, aromatases are localized to Leydig and Sertoli cells. ${ }^{7}$ It reversibly inhibits the aromatase, which is an enzyme that converts the androgen precursors in adipose tissue to estrogen. ${ }^{8}$ Blocking estrogen production by inhibiting aromatization will stop the conversion of androstenedione and testosterone to estrogen. In the last two decades, studies have reported improved semen quality in men with normal gonadotropins and idiopathic oligozoospermia treated with aromatase inhibitors. ${ }^{5,9}$ Clinical use of aromatase inhibitors has been applied to idiopathic infertility with the intent of reducing estrogenic effects on the male reproductive system, specially by reducing feedback inhibition of the hypothalamic-pituitary-gonadal axis. Since male detect testosterone levels by the pituitary primarily by estrogen levels rather than testosterone alone, inhibition of estrogen production by an aromatase inhibitor can be a potent stimulant for increased $\mathrm{LH}$ production and hence intratesticular and circulating testosterone levels. ${ }^{6}$

The aim of this study was to evaluate the effect of aromatase inhibitor, letrozole in infertile male having oligozoospermia (sperm count $\leq 10$ million/ml), low serum testosterone $(<300 \mathrm{ng} / \mathrm{dl})$ level and Testosterone to estradiol ratio $<10$.
General objective: To evaluate the effect of aromatase inhibitor, letrozole in infertile male having oligozoospermia (sperm count $\leq 10$ million/ml), low serum testosterone $(<300 \mathrm{ng} / \mathrm{dl})$ level and Testosterone to estradiol ratio $<10$.

Specific Objectives: To determine the effect of aromatase inhibitor, letrozole upon sperm count. To determine the effect of aromatase inhibitor, letrozole upon sperm motility. To determine the effect of letrozole on total motile count.

\section{METHODS}

This was a prospective study and was conducted in the Department of Reproductive Endocrinology and Infertility at Bangabandhu Sheikh Mujib Medical University, Dhaka, Bangladesh during the period from May 2019 to April 2020. The sample size was 36 and all of them were men. Statistical analysis was carried out by using IBM Statistical Package for Social Sciences version 25 for windows (SPSS version 25.0).

\section{Inclusion criteria}

Age 25 to 45 years, Patients with oligozoospermia (presence of sperm concentration $\leq 10$ million per $\mathrm{ml}$ in both semen samples collected 30 days apart),Serum testosterone concentration $<300 \mathrm{ng} / \mathrm{dl}$, Testosterone to estradiol ratio $<10$.

\section{Exclusion criteria}

Patients who have additional causal factors of infertility such as varicocele or ejaculatory duct obstruction. Patients who have undergone surgery for male factor infertility such as varicocele and ejaculatory duct obstruction. Personal history of regular intake of alcohol, smoking, use of drugs like antipsychotics, antihypertensive, antiepileptic, dopamine antagonists or recreational drugs. Suffering from infections like sexually transmitted disease and tuberculosis. Known case of systemic and chronic disease like diabetes mellitus, hypothyroidism, renal or liver disease. Patients taking fertility treatment or under oral or intravenous fertility medication in the recent 2 months.

\section{RESULTS}

In this study, the sample size was 30. The demographic characteristics of the subjects (Table 1) showed that majority patients belonged to age 31-35 years, which was $15(50 \%)$ in study group. The mean age was found $33.37 \pm 3.864$ years. Regarding monthly income, 14 (46.7\%) patients earned monthly 25000 - $<50000$ taka, $11(36.7 \%)$ earned 10000 - <25000 taka and $4(13.3 \%)$ earned $<10000$ taka. Majority patients came from urban area, which was $22(73.3 \%)$. Regarding coital frequency, most of the patients $17(56.7 \%)$ performed coitus $2-3$ per week and mean coital frequency was found $2.37 \pm 0.556$. It 
was observed that there was no sexual dysfunction among the total 30 patients.

Table 1: Distribution of the study patients by demographic variables $(n=30)$.

\begin{tabular}{|c|c|c|c|}
\hline \multicolumn{2}{|c|}{ Demographic parameter } & $\mathbf{n}$ & $\%$ \\
\hline \multirow{6}{*}{ Age (in years) } & $\leq 30$ & 9 & 30 \\
\hline & $31-35$ & 15 & 50 \\
\hline & $36-40$ & 5 & 16.7 \\
\hline & $41-45$ & 1 & 3.3 \\
\hline & Mean \pm SD & \multicolumn{2}{|c|}{$33.37 \pm 3.864$} \\
\hline & 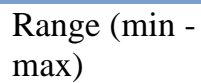 & \multicolumn{2}{|c|}{$27-41$} \\
\hline \multirow{4}{*}{ Occupation } & Govt. service & 5 & 16.7 \\
\hline & Business & 5 & 16.7 \\
\hline & Private job & 8 & 26.7 \\
\hline & Others & 12 & 40 \\
\hline \multirow{6}{*}{$\begin{array}{l}\text { Monthly } \\
\text { income (Taka) }\end{array}$} & $<10000$ & 4 & 13.3 \\
\hline & $\begin{array}{l}10000- \\
<25000\end{array}$ & 11 & 36.7 \\
\hline & $\begin{array}{l}25000- \\
<50000\end{array}$ & 14 & 46.7 \\
\hline & $>50000$ & 1 & 3.3 \\
\hline & Mean \pm SD & \multicolumn{2}{|c|}{$24000 \pm 7700$} \\
\hline & $\begin{array}{l}\text { Range (min- } \\
\max \text { ) }\end{array}$ & \multicolumn{2}{|c|}{$5500-50000$} \\
\hline \multirow{2}{*}{ Habitat } & Urban & 22 & 73.3 \\
\hline & Rural & 8 & 26.7 \\
\hline
\end{tabular}

Regarding type and duration of infertility of the patients, it was observed that primary infertility was found in 29 $(96.7 \%)$ and secondary infertility in $1(3.3 \%)$. Maximum $(83.3 \%)$ men had duration of infertility within 5-10 years and the mean \pm SD was $1.97 \pm 0.41$ years. Regarding BMI, $18(60 \%)$ belonged to overweight group $(25-29.9 \mathrm{~kg} / \mathrm{m} 2)$ and the mean BMI was $25.41 \pm 1.52 \mathrm{~kg} / \mathrm{m} 2$. Majority of the patients had isolated Oligozoospermia $15(50 \%), 8$ (26.7\%) had oligoasthenoteratozoospermia and 7 (23.3\%) had oligoasthenozoospermia. Regarding endocrine evaluation, mean serum FSH was $5.14 \pm 1.14 \mathrm{IU} / \mathrm{L}$, mean serum LH was $5.19 \pm 1.34 \mathrm{mIU} / \mathrm{ml}$, mean serum testosterone was $217.96 \pm 15.70 \mathrm{ng} / \mathrm{dl}$, mean serum estradiol was $40.69 \pm 5.92 \mathrm{pg} / \mathrm{ml}$ and mean T: E2 ratio was found $5.48 \pm 1.01$.

Table 2: Distribution of the study patients $(n=30)$ by duration of infertility, BMI and type of semen parameters.

\begin{tabular}{|c|c|c|c|}
\hline \multicolumn{2}{|c|}{ Characteristics } & n & $\%$ \\
\hline \multirow{5}{*}{$\begin{array}{l}\text { Duration of } \\
\text { infertility } \\
\text { (in years) }\end{array}$} & $<5$ & 3 & 10 \\
\hline & 10-May & 25 & 83.3 \\
\hline & $>10$ & 2 & 6.7 \\
\hline & Mean \pm SD & 1.9 & 414 \\
\hline & Range (min - max) & 15 & \\
\hline \multirow{4}{*}{$\begin{array}{l}\text { BMI } \\
\left(\mathrm{Kg} / \mathbf{m}^{2}\right)\end{array}$} & $18-24.9$ & 12 & 40 \\
\hline & $25-29.9$ & 18 & 60 \\
\hline & Mean \pm SD & 25 . & \\
\hline & Range (min-max) & $23-$ & \\
\hline \multirow{3}{*}{$\begin{array}{l}\text { Semen } \\
\text { parameter }\end{array}$} & Oligozoospermia & 15 & 50 \\
\hline & $\begin{array}{l}\text { Oligoasthenozoosp } \\
\text { ermia }\end{array}$ & 7 & 23.3 \\
\hline & $\begin{array}{l}\text { Oligoasthenoterato } \\
\text { zoospermia }\end{array}$ & 8 & 26.7 \\
\hline
\end{tabular}

Table 3: Distribution of the study patients by endocrine evaluation $(n=30)$.

\begin{tabular}{|c|c|c|}
\hline \multirow[t]{2}{*}{ Endocrine evaluation } & \multicolumn{2}{|l|}{ n (30) } \\
\hline & Mean \pm SD & $\begin{array}{l}\text { Range (min- } \\
\text { max) }\end{array}$ \\
\hline S.FSH (IU/L) & $05.14 \pm 01.14$ & 03.49-07.97 \\
\hline S.LH ( mIU/ml) & $05.19 \pm 01.34$ & $03.40-08.70$ \\
\hline S. Testosterone (ng/dl) & $217.96 \pm 15.70$ & $194.23-260.0$ \\
\hline S. Estradiol (pg/ml) & $40.69 \pm 05.92$ & $29.13-49.51$ \\
\hline $\begin{array}{l}\text { Testosterone: } \\
\text { Estradiol ratio }\end{array}$ & $05.48 \pm 01.01$ & 04.03-07.83 \\
\hline
\end{tabular}

Table 4: Mean pretreatment and post treatment sperm parameters $(n=30)$.

\begin{tabular}{|llll|}
\hline Sperm parameter & Pre-treatment & Post treatment & P Value \\
\hline Ejaculate volume & Mean \pm SD & Mean \pm SD & 0.326 \\
\hline Sperm count(million/ml) & $01.93 \pm 0.28$ & $1.900 \pm 0.203$ & 0 \\
\hline Motility (\%) & $05.93 \pm 2.49$ & $15.83 \pm 10.43$ & 0 \\
\hline $\begin{array}{l}\text { Total motile sperm count } \\
\text { (million) }\end{array}$ & $37.03 \pm 19.10$ & $52.50 \pm 17.92$ & 0 \\
\hline
\end{tabular}

The difference was significant for sperm count, motility and total motile sperm count but not for ejaculate volume. Subgroup or interaction analysis was done for variables affecting improvement or response defined by the rise in total motile count to more than 10 million. Association of the type of oligozoospermia (severe or moderate) with response defined by rise in total motile count to more than 10 million was analyzed by $2 \times 2$ contingency table 
and Fishers exact test. The association was not statistically significant. Among the patients, only two had mild headache, which subsided with time and was not the reason to discontinue the treatment. Another two patients reported a decrease in libido after three months of treatment. However, they did not consider it severe enough to discontinue the drug.

Table 5: Association of the type of oligozoospermia with response defined by rise of TMC to more than $10 \mathrm{million}$.

\begin{tabular}{|c|c|c|c|}
\hline Type of Oligozoospermia & $\begin{array}{l}\text { Not improved to } \\
\text { TMC }>10 \text { million }\end{array}$ & $\begin{array}{l}\text { Improved to TMC >10 } \\
\text { million }\end{array}$ & P value \\
\hline $\begin{array}{l}\text { Moderate oligozoospermia (sperm } \\
\text { concentration 5-10 million } / \mathrm{ml} \text { ) }\end{array}$ & $45.50 \%$ & $54.50 \%$ & \multirow[b]{2}{*}{0.43} \\
\hline $\begin{array}{l}\text { Severe oligozoospermia (sperm } \\
\text { concentration }<5 \text { million } / \mathrm{ml} \text { ) }\end{array}$ & $33.30 \%$ & $58.30 \%$ & \\
\hline
\end{tabular}

\section{DISCUSSION}

This prospective observational study was carried out with an aim to evaluate the effect of letrozole, administered at a dose of $2.5 \mathrm{mg}$ daily for 4 months, upon semen parameters of infertile men. The increase in sperm concentration, sperm motility and total motile sperm count at the completion of treatment were statistically significant $(\mathrm{p}<0.001)$. There was pregnancy in four cases during study period and they were excluded from analysis. BMI had an extensive range, with a mean of about $25.41 \pm 1.52 \mathrm{~kg} / \mathrm{m} 2$ in the present study. In Peivandi et al. $^{10}$ the mean BMI was $27 \pm 3.395 \mathrm{~kg} / \mathrm{m} 2$, which is comparable to that of current study. It was observed that the ratio of testosterone to estradiol was lower among overweight men (BMI>25) than men with lower BMI. Obese men have a threefold increase in the prevalence of oligozoospermia when compared to men with normal BMI. In this present study it was observed that mean serum testosterone was $217.96 \pm 15.70 \mathrm{ng} / \mathrm{dl}$, mean serum estradiol was $40.69 \pm 5.92 \mathrm{pg} / \mathrm{ml}$ and mean T: E2 ratio was $5.48 \pm 1.01$. In Shoshany et al. study the mean serum testosterone was $258 \pm 10.80 \mathrm{ng} / \mathrm{dl}$, mean serum estradiol was $40.80 \pm 1.90 \mathrm{pg} / \mathrm{ml}$ and mean $\mathrm{T}$ : $\mathrm{E} 2$ ratio was $6.98 \pm 0.33$, which is almost similar with the present study. Saylam et al. in a prospective study on 27 infertile men with testosterone to estradiol ratio $<10$ taking letrozole $2.5 \mathrm{mg}$ daily for 6 months, examined the effect of letrozole on BMI, hormonal parameters and semen parameters. $^{11,12}$ After treatment with letrozole, oligozoospermic men showed significant improvement in sperm count $(\mathrm{p}=0.03)$, total motile sperm count $(\mathrm{p}=$ $0.016)$ and ejaculate volume $(\mathrm{p}=0.031)$. Additionally, 2 of 10 oligozoospermic men achieved spontaneous pregnancy. The findings of this study corresponded to the present study except the ejaculate volume. They concluded that the use of letrozole in infertile men with low testosterone to estradiol ratio could be effective in improving in hormonal and sperm parameters. Peivandi et al. conducted a quasi-experimental clinical trial on 41 oligozoospermic infertile men with letrozole $2.5 \mathrm{mg}$ daily for 4 months to see the effect of letrozole on semen parameters and hormonal profile. ${ }^{10}$ After letrozole treatment the sperm concentration, sperm motility and sperm forward motion significantly increased. The findings corresponded to the present study. Gregoriou et al. conducted a prospective nonrandomized comparative study between letrozole and anastrazole to see the hormonal changes and seminal parameters following treatment with aromatase inhibitors in 29 infertile men with low testosterone estradiol ratio $(<10) .{ }^{13}$ The patients were treated with either letrozole $2.5 \mathrm{mg}$ or anastrazole 1 $\mathrm{mg}$ daily for 6 months. Both treatment groups showed statistically significant increase in hormonal and semen parameters including ejaculate volume $(\mathrm{p}<0.001)$, sperm count $(\mathrm{P}<0.001)$ and sperm motility $(\mathrm{p}<0.001)$. The findings of semen parameters were similar to the present study except the ejaculate volume. They concluded that some men with severe oligozoospermia, low testosterone levels and normal gonadotropin concentration may have a treatable endocrinopathy. Raman and Schlegel treated 140 subfertile men with abnormal testosterone to estradiol ratios using either testolactone $100-200 \mathrm{mg}$ or anastrazole $1 \mathrm{mg}$ daily. ${ }^{9}$ A comparison of the efficacy of these two therapies on both hormonal and semen parameters showed similar effects. There was significant increase in sperm concentration (from $5.5 \mathrm{million} / \mathrm{ml}$ to 15.6 million $/ \mathrm{ml}$ ) and sperm motility ( $14.7 \%$ to $21 \%$ ) but no pregnancies were reported during treatment. The findings agreed with the results of the present study in sperm concentration and motility, but disagreed with the pregnancy data. However, those authors included patients with Klinefelter syndrome and varicocele. Patry et al. reported that after the treatment of aromatase inhibitor, letrozole, orally once daily for 4 months, final testicular biopsy showed normal spermatogenesis in one man with primary infertility, normal serum FSH level and pattern of non-obstructive azoospermia on a testicular biopsy. ${ }^{14}$ In a retrospective study by Shoshany et al. showed that 21 subfertile hypoandrogenic oligospermic men were treated with anastrazole $1 \mathrm{mg}$ daily for 6 months and sperm concentration and total motile sperm count were significantly improved in 18 out of 21 oligospermic male. The results were similar to the present study. ${ }^{11}$ As early as 1981, in an uncontrolled study, Vigersky and Glass investigated the effects of testolactone $(1 \mathrm{~g} / \mathrm{d})$ in 10 
oligospermic men. ${ }^{15}$ These authors reported that $80 \%$ of men treated demonstrated an increase in sperm count, and there was no change observed in sperm motility. In Pavlovich et al. study, 63 subfertile patients with testosterone to estradiol ratio of 6.9 compared with 14.5 in fertile controls. ${ }^{5}$ In a subset of 25 patients with oligozoospermia an increase in semen parameters after anastrazole therapy was observed. These authors proposed a threshold testosterone to estradiol ratio of 10 , representing the lowest 20th percentile of fertile subjects in the control group. In the present study the $\mathrm{T} / \mathrm{E}_{2}$ ratios were $<10$ and the mean was $5.48 \pm 1.01$ and semen parameters significantly improved after letrozole treatment. So, the results of this study are in agreement with that of the present study. In a randomized, controlled trial conducted by Clark and Sherins in Georgia, the effect of treatment with aromatase inhibitors on idiopathic oligozoospermia has been studied. In that study, 25 patients with idiopathic oligozoospermia were treated with testolactone $2 \mathrm{~g} /$ day or placebo for 8 months, followed by cross over for 8 months. Sperm parameters remained unchanged during treatment with testolactone and placebo and no pregnancy occurred during the 16 months follow up. ${ }^{16}$

These data have shown that long term administration of testolactone was not effective in the treatment of infertility due to idiopathic oligozoospermia. ${ }^{16}$ The findings of the Clark and Sherins study differed from the present study. ${ }^{16}$ The subjects in their study had normal testosterone concentrations and likely testosterone to estradiol ratios above the threshold of 10 , because the mean testosterone and mean estradiol in the placebo and testolactone inhibition arms were $479 \pm 50 \mathrm{ng} / \mathrm{dl}$ and $27.2 \pm 2.3 \mathrm{pg} / \mathrm{ml}$, and $521 \pm 6.0 \mathrm{ng} / \mathrm{dl}$ and $23.2 \pm 1.8 \mathrm{pg} / \mathrm{ml}$ respectively. The estradiol and testosterone concentrations did not change with treatment during the trial. The reason for the different results of seminal parameters from the present study was most likely to be related to the use of testolactone, a first generation aromatase inhibitor with less potency. In this present study, letrozole was used which is 20 times more potent in inhibiting the aromatase enzyme than other aromatase inhibitors. The third generation aromatase inhibitors have a greater estrogen inhibition than the first generation and second generations, which is one thousand times more potent.

Letrozole in contrast to the previous two generations, acts selectively and does not interfere with the secretions of glucocorticoids, mineralocorticoids and/or thyroxin secretion. ${ }^{17}$ So, a reasonable conclusion from Helo et al and Clark and Sherins study is that men who are not hypoandrogenic or who have abundant sperm concentration, may not benefit from treatment with aromatase inhibitors. ${ }^{18,16}$ In a prospective study Shuling et al. treated fifteen men with idiopathic severe oligozoospermia (sperm concentration $<5 \mathrm{million} / \mathrm{ml}$ ) with normal testosterone to estradiol ratio $(>10)$ by letrozole, $2.5 \mathrm{mg}$ daily for 4 months. ${ }^{19}$ After treatment there was 5.5-fold increase in sperm concentration $(\mathrm{p}=<0.0001)$. This finding agreed with the finding of present study and heralds a possibility that letrozole may be effective in oligospermic males with normal testosterone to estradiol ratio. No study described so far defined an outcome of improvement to TMSC to more than 10 million, a threshold for reasonable success in intrauterine insemination, In the present study, $90 \%$ of men with oligozoospermia demonstrated significant increase in sperm concentrations and the total motile sperm count (>10 million) was improved in $74 \%$ patients. So more than $70 \%$ of the oligozoospermic patients became eligible for IUI considering a total motile sperm count threshold $>10$ million, and these patients could consequently choose an alternative to IVF.

As a rule, in the present study, letrozole was safe and well tolerated. In most of the patients, no severe side effects were observed with the treatment. Mild headache was present in two men, decreased libido in two men, but not severe enough to discontinue treatment. This finding may suggest that estrogen could play a role in supporting libido. In Cavallini et al. study, six patients demonstrated loss of libido, two patients had cutaneous rashes and one case developed nervousness. $^{20}$

In Gregoriou et al. study, an asymptomatic mild and transient rise in serum liver enzymes, serum glutamic oxaloacetic transaminase (SGOT) and serum glutamic pyruvic transaminase (SGPT) was seen in one patient. ${ }^{13}$ In addition, transient weakness, nausea, mild headache in a few patients, not enough to discontinue treatment. In Shuling et al. side effects like loss of libido, headaches, fatigue, and dry mouth were reported. ${ }^{19}$ In Saylam et al. study only mild headaches were reported with letrozole treatment. ${ }^{12}$ The side effects subsided with time and all patients continued treatment. Letrozole has better tolerability than anastrazole. In Shoshany et al. study, two patients reported joint and tendon pain and swelling in their limbs and discontinued anastrazole treatment. ${ }^{11}$

One patient developed decreased libido, irritability and depression, bilateral breast tenderness, ocular pruritus and dry mouth, but these subsided with time and they continued treatment. One patient reported transient bilateral ankle swelling, which resolved while continuing treatment. The side effects of letrozle or another aromatase inhibitor for short term use are more or less similar in the present study and related previous study and they are well tolerated by most of the patients and not the reason to discontinue treatment. There are no available data concerning possible risks about the long term use of aromatase inhibitors in men, but from the available data from the use of aromatase inhibitors in post- menopausal women with breast cancer it seems that the main potential concerns are about the risk of development of osteoporosis and a possible mild increase in cholesterol levels at 5 years use of letrozole. In a retrospective study, Shoshany et al. reported two patients 
suffered from arthralgia and possibly from arthritis after treatment with anastrazole for 4 months. ${ }^{11}$

So, a word of caution should be mentioned regarding the possible risk of decreased bone density due to aromatase inhibitors treatment.

This is especially true in a population of men with hypoandrogenism, who are more prone to having decreased bone density to begin with.

The significance of estrogen in the male physiology is gradually unfolding. The optimal concentrations of estradiol may be related to increased bone resorption and decrease in bone mass density ${ }^{21}$. Consequently, long term skeletal safety remains an issue of concern, and it is important to consider performing bone density scans in patients treated with aromatase inhibitors for longer periods of time.

Limitation: The study did not include a control group. This study only recruited the patients seeking treatment. Studies with randomized control trial designs are needed to show good evidence of the efficacy of aromatase inhibitor, letrozole. Serum testosterone and estradiol levels were measured once, relying on enzyme immunoassays, which may reduce the reliability of the diagnosis of low testosterone and testosterone to estradiol ratios. The study did not have data on post treatment serum testosterone, estradiol and testosterone to estradiol ratios, which may have provided added information to better define the efficacy of letrozole.

\section{CONCLUSION}

In summary it can be said that sperm count, motility and total motile sperm count improve significantly after 4 months' treatment periods with letrozole in oligozoospermic infertile men with a low serum testosterone to estradiol ratio.

Letrozole, an aromatase inhibitor, may be used effectively to improve semen parameters and fertility potential (including spontaneous pregnancy) in this subgroup of infertile men with eugonadotropic hypogonadism.

Further community based or multicenter, randomized, controlled studies can be undertaken by including large number of patients and letrozole can be given to the oligozoospermic men before intrauterine insemination or ART cycles of treatment. The studies may include oligospermic males with both normal and reduced testosterone to estradiol ratios.

Funding: No funding sources Conflict of interest: None declared

Ethical approval: The study was approved by the Institutional Ethics Committee

\section{REFERENCES}

1. Agarwal A, Mulgund A, Hamada A, Chytte MR, A unique view on male infertility around the globe. Reproductive Biology and Endocrinol. 2015;13:37.

2. Esteves SC, Miyaoka R, Agarwal A. An update on the clinical assessment of the infertile male. Clinics. 2011;66:691-700.

3. Jarow JP, Zirkin BR. The androgen microenvironment of the human testis and hormonal control of spermatogenesis. Ann N Y Acad Sci. 2005; 1061:208-20.

4. Bharti S, Misro, MM, Rai U. Clomiphene citrate potentiates the adverse effects of estrogens on rat testis and down-regulates the expression of steroidogenic enzyme genes. Fertil Steril. 2013;99:140-8.

5. Pavlovich CP, King P, Goldstein M, Schlegel PN. Evidence of a treatable endocrinopathy in infertile men. J Urol. 2001;165:837-41.

6. Santen RJ. Feedback control of luteinizing hormone and follicle- stimulating hormone secretion by testosterone and estradiol in men: physiological and clinical implications. Clin Biochem. 1981;14:243-51.

7. Inkster S, Yue W, Brodie A, Human testicular aromatase: immunocytochemical and biochemical studies. J Clin Endocrinol Metab. 1995;80:1941-7.

8. McArthur HL, Morris PG. Aromatase inhibitor strategies in metastatic breast cancer. Int J Women's Health. 2010;1:67-72.

9. Raman JD, Schlegel PN. Aromatase inhibitors for male infertility. J Urol. 2002;167:624-9.

10. Peivandi S, Hamed J, Mina A, Ebadi A. Effect of letrozole on spermogram parameters and hormonal profile in infertile men: A clinical trial study. Endocrine Regulations. 2019;53:231-6.

11. Shoshany O, Abhyankar N, Mufarreh N, Daniel G, Niederberger C. Outcomes of anastrazole in oligozoospermic hypoandrogenic subfertile men. Fertil Steril. 2017;107(3):589-94.

12. Saylam B, Efesoy O, Cayan S. The effect of aromatase inhibitor letrozole on body mass index, serum hormones, and sperm parameters in infertile men. Fertil Steril. 2011;95:809-11.

13. Gregoriou O, Bakas P, Grigoriadis C, Creatsa M, Hassiakos D, Creatsas G. Changes in hormonal profile and seminal parameters with use of aromatase inhibitors in management of infertile men with low testosterone to estradiol ratios. Fertil Steril. 2012;98:48-51.

14. Patry G, Jarvi K, Grober ED, Lo KC. Use of the aromatase inhibitor letrozole to treat male Infertility. Fertil Steril. 2009;92:892.

15. Vigersky RA, Glass AR. Effects of testolactone on the pituitary-testicular axis in oligozoospermic men. J Clin Endocrinol Metab. 1981;52:897-902.

16. Clark RV, Sherins RJ. Treatment of men with idiopathic oligozoospermic infertility using the aromatase inhibitor, testolactone. Results of a 
double-blinded, randomized, placebo-controlled trial with crossover. J Androl. 1989;10:240-7.

17. Smith IE, Norton A. Fadrozole and letrozole in advanced breast cancer: clinical and biochemical effects. Breast cancer Res Treat. 1998;49:67-77.

18. Helo S, Ellen J, Mechlin C, Feustel P, Grossman M, Ditkoff E, et al. A randomized prospective doubleblind comparison trial of clomiphene citrate and anastrazole in raising testosterone in hypogonadal infertile men. J Sex Med. 2015;12:1761-9.

19. Shuling L, Sie KUi. ML, Saffari SE, et al. Do men with normal testosterone-estyradiol ratios benefit from letrozole for the treatment of male infertility? Reproductive Biomed Online. 2019;38(1):39-45.
20. Cavallini G, Biagiotti G, Bolzon E. Multivariate analysis to predict letrozole efficacy in improving sperm count of non-obstructive azoospermic and cryptozoospermic patients: A pilot study. Asian J Androl. 2013;15:806-11.

21. de Ronde W, de Jong FH. Aromatase inhibitors in men: effects and therapeutic options. Reprod Biol Endocrinol. 2011;9:93.

Cite this article as: Jahan I, Ishrat $\mathrm{S}$, Banu J, Fatima P, Ansary SA, Afrin S. Effect of aromatase inhibitor, letrozole on semen parameters in eugonadotropic hypoandrogenic men with oligozoospermia. Int J Reprod Contracept Obstet Gynecol 2021;10:1284-90. 